\title{
Tuning catalytic selectivity of propane oxidative dehydrogenation via surface polymeric phosphate modification on nickel oxide nanoparticles
}

\author{
Kaimin Du a, Mengjia Hao a, Zhinian Li a , Wei Hong a, Juanjuan Liu b, Liping Xiao a, Shihui Zou a,\$, \\ Hisayoshi Kobayashi c,\#, Jie Fan ${ }^{\text {a,* }}$ \\ a Key Lab of Applied Chemistry of Zhejiang Province, Department of Chemistry, Zhejiang University, Hangzhou 310027, Zhejiang, China \\ b College of Materials \& Environmental Engineering, Hangzhou Dianzi University, Hangzhou 310018, Zhejiang, China \\ c Department of Chemistry and Materials Technology, Kyoto Institute of Technology, Matsugasaki, Sakyo-ku, Kyoto 606-8585, Japan
}

\section{A R T I C L E I N F O}

\section{Article history:}

Received 4 October 2018

Accepted 12 November 2018

Published 5 July 2019

\section{Keywords:}

Nickel oxide nanoparticle

Surface polymeric phosphate

Propane oxidative dehydrogenation

Tuning selectivity

Adsorption

\begin{abstract}
A B S T R A C T
Thermal stability has long been recognized as a major limitation for the application of ligand modification in high-temperature reactions. Herein, we demonstrate polymeric phosphate as an efficient and stable ligand to tune the selectivity of propane oxidative dehydrogenation. Beneficial from the weakened affinity of propene, $\mathrm{NiO}$ modified with polymeric phosphate shows a selectivity 2-3 times higher than $\mathrm{NiO}$ towards the production of propene. The success of this regulation verifies the feasibility of ligand modification in high-temperature gas-phase reactions and shines a light on its applications in other important industrial reactions.
\end{abstract}

(C) 2019, Dalian Institute of Chemical Physics, Chinese Academy of Sciences. Published by Elsevier B.V. All rights reserved.
Engineering the surface structure of a catalyst to improve its selectivity to target products is an important focus in heterogeneous catalysis [1-5]. Conventionally, this engineering mainly focuses on the regulation of composition, morphology, particle size and support, which can potentially alter the steric and electronic properties of the catalyst surface [6-10]. Recently, surface ligand modification has emerged as an effective and elegant strategy to tune the catalytic selectivity of metal nanoparticles (NPs). By modifying $\mathrm{Pd} / \mathrm{Al}_{2} \mathrm{O}_{3}$ with alkanethiol coatings, Marshall et al. [11] improved the selectivity of 1-epoxybutane from $11 \%$ to $94 \%$ at equivalent reaction conditions and 1-epoxy-3-butene conversions. On the other hand, ligand modification offers a fine control over the steric or electronic structure of metal nanoparticles without introducing external active sites, which provides ideal models to investigate the reaction mechanism. For example, by utilizing ethylenediamine as an efficient ligand to tune the surface electronic structure of Pt nanowires, Chen et al. [3] revealed that the in-

\footnotetext{
* Corresponding author. Tel/Fax: +86-571-87952338; E-mail: jfan@zju.edu.cn

\# Corresponding author. E-mail: hisabbit@yahoo.co.jp

\$Corresponding author. E-mail: xueshan199@163.com

This work was supported by the National Natural Science Foundation of China (91545113, 21703050), the China Postdoctoral Science Foundation (2017M610363, 2018T110584), Shell Global Solutions International B. V. (PT71423, PT74557), the Fok Ying Tong Education Foundation (131015), and the Science \& Technology Program of Ningbo (2017C50014).

DOI: 10.1016/S1872-2067(18)63199-7 | http://www.sciencedirect.com/science/journal/18722067 | Chin. J. Catal., Vol. 40, No. 7, July 2019
} 
terfacial electronic effect played a key role in the selective catalysis. The electron-rich Pt surface favored the adsorption of electron-deficient reactants over electron-rich substrates, which consequently enhanced the selectivity of phenylhydroxylamine in nitrobenzene reduction. Nevertheless, to the best of our knowledge, there is no report about utilizing ligand modification to regulate the catalytic selectivity of high-temperature $\left(>300^{\circ} \mathrm{C}\right)$ gas-phase reactions due to the volatility and limited thermal stability of traditional organic ligands [2]. The successful discovery of thermal-stable ligands will eventually overcome this obstacle and extend this effective modification strategy to some important high-temperature industrial reaction systems.

Here, propane oxidative dehydrogenation (PODH) is chosen as a model reaction as it is a promising route for the industrial production of propene $[12,13]$. Conventionally, the sequential oxidation of propene to $\mathrm{CO}_{2}$ is thermodynamic favorable, which limits the catalytic selectivity towards propene $[14,15]$. In this work, we demonstrate that the modification of polymeric phosphate on $\mathrm{NiO}$ nanoparticles (NPs) improves its selectivity to propene by 2-3 times at equivalent conversion of propane. Kinetic studies and DFT calculations reveal that the presence of polymeric phosphate can weaken the affinity of propene, which consequently reduce the possibility of over-oxidation and improve the selectivity towards propene.

Polymeric phosphate modified $\mathrm{NiO}$ was prepared by a post-treatment of NiO NPs in phosphate solution, followed by a high-temperature calcination to in situ generate polymeric phosphate (Scheme S1, Supporting Information). The content of $\mathrm{P}$ on $\mathrm{NiO}$ surface could be regulated by the concentration of phosphate solution. The corresponding catalysts were denoted as NiO- $x \mathrm{SPP}$, where $x$ is the molar ratio of $\mathrm{P}$ to $\mathrm{Ni}$ in the treatment solution.

Transmission electron microscopy images (Fig. S1) reveal that the modification of polymeric phosphate does not significantly change the morphology of NiO NPs. The size of NiO-1.8SPP $(\sim 11.4 \mathrm{~nm})$ is slightly smaller than fresh NiO NPs $(\sim 14.0 \mathrm{~nm})$, likely due to etching of $\mathrm{NiO}$ during the post-treatment. High-resolution transmission electron microscopy image (Fig. 1(a)) of NiO-1.8SPP shows lattice fringes with spacing of $0.21 \mathrm{~nm}$, which could be readily attributed to the $\mathrm{NiO}(200)$ plane [16]. Besides, all NiO-SPP samples display similar X-ray diffraction patterns with NiO (Fig. 1(b)). No additional peaks belonging to other species are observed, excluding the structure change of NiO.

The structure of phosphate on NiO-SPP is determined by Fourier transform infrared spectra (FT-IR). Comparing to $\mathrm{NiO}$ NPs, all NiO-SPP samples exhibit obvious phosphorous peaks (Fig. 1(c)), indicating that phosphate is successfully modified onto the $\mathrm{NiO}$ surface. The peaks at 1069 and $1174 \mathrm{~cm}^{-1}$ can be assigned to phosphate $\left(\mathrm{PO}_{4}^{3-}\right)$ while two other peaks at 974 and $890 \mathrm{~cm}^{-1}$ are characteristic peaks of polymeric phosphate (P-O-P) $[17,18]$. The latter is detected only in the samples after calcination (Fig. S2), suggesting that polymeric phosphate is in situ generated by the high-temperature calcination. This result is further confirmed by the obvious upshift of P $2 p$ X-ray photoelectron spectroscopy (XPS) peak after calcination (Fig. 1(f) and Fig. S3). Taking NiO-1.8SPP as an example, the P $2 p$ XPS peak before calcination locates at $132.9 \mathrm{eV}$, corresponding to $\mathrm{PO}_{4}^{3-}$ species. After calcination, the peak upshifts to $133.5 \mathrm{eV}$, (a)

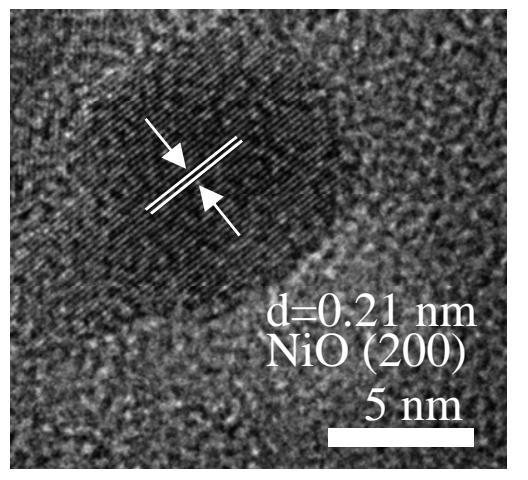

(d)

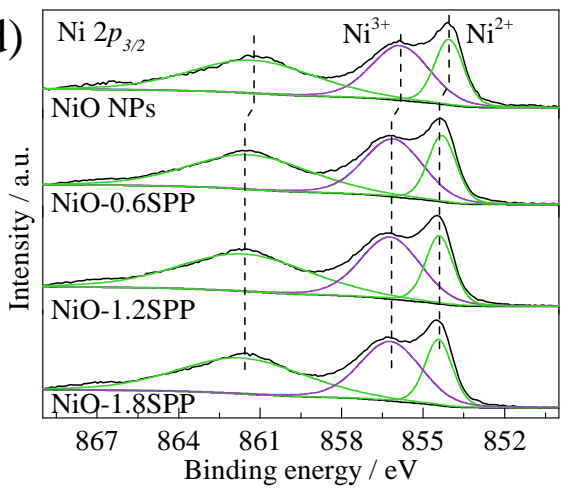

(b)

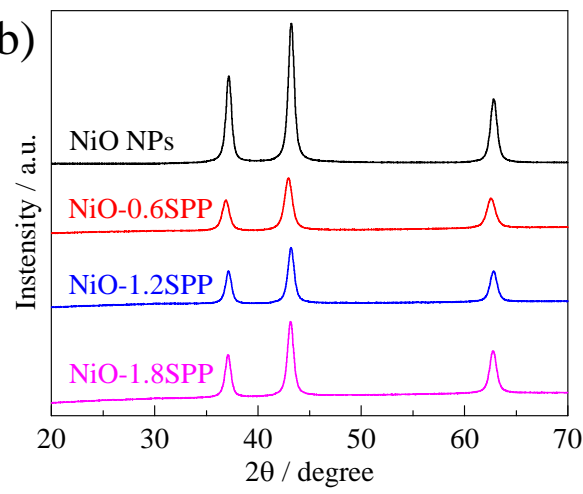

(e)

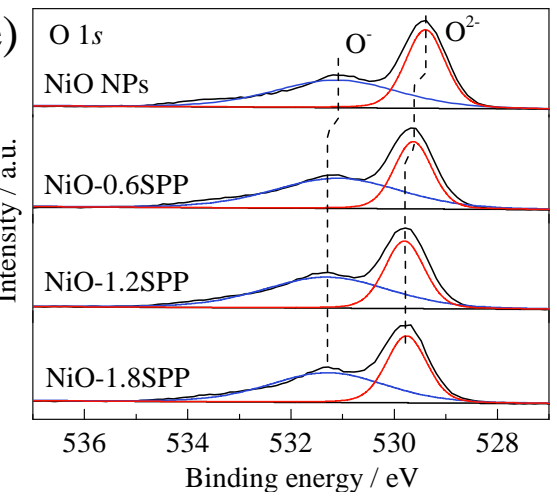

(c)

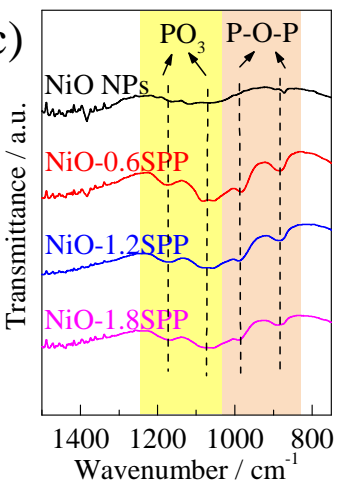

(f)

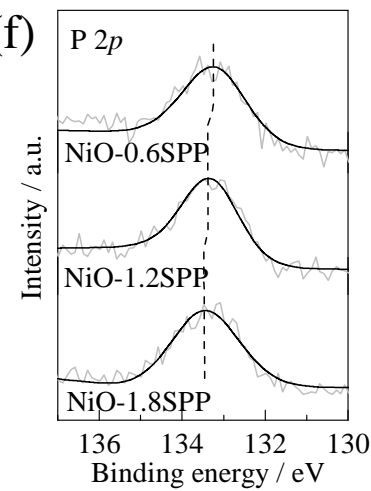

Fig. 1. (a) HRTEM image of NiO-1.8SPP; (b) XRD patterns, (c) FT-IR spectra, (d) Ni $2 p_{3 / 2}$ and (e) $01 s$ XPS spectra of NiO NPs, NiO-0.6SPP, NiO-1.2SPP and NiO-1.8SPP; (f) P $2 p$ XPS spectra of NiO-0.6SPP, NiO-1.2SPP and NiO-1.8SPP. 
corresponding to $\mathrm{P}_{2} \mathrm{O}_{7}{ }^{4-}$. The $0.6 \mathrm{eV}$ upshift clearly indicates the transformation of phosphate to polymeric phosphate. Besides, the presence of $\mathrm{P}$ ligand after a high-temperature $\left(500^{\circ} \mathrm{C}\right) \mathrm{cal}-$ cination also implies a good thermal stability of polymeric phosphate, consistent with the themogravimetric analysis (Fig. S4).

The presence of polymeric phosphate changes the surface electronic structure of NiO NPs. As for NiO NPs, the Ni $2 p$ peak at $855.8 \mathrm{eV}$ is attributed to $\mathrm{Ni}^{3+}$ species, and the peak at 854.0 $\mathrm{eV}$ is assigned to $\mathrm{Ni}^{2+}$ species along with its satellite peak at $861.3 \mathrm{eV}$ (Fig. 1(d)) [19]. However, after modified by polymeric phosphate, all these three peaks upshift. Similar upshift is observed for $01 s$ as well, indicating that polymeric phosphate can withdraw electrons from NiO NPs. Specifically, NiO-1.8SPP shows the highest upshift. A $0.4 \mathrm{eV}$ upshift in $\mathrm{Ni} 2 p$ and a $0.3 \mathrm{eV}$ upshift in $01 s$ are observed, indicating a strong interaction between $\mathrm{NiO}$ and polymeric phosphate. Besides, the modification of polymeric phosphate also shifts the reduction temperatures of $\mathrm{NiO}$ and desorption temperature of oxygen to higher

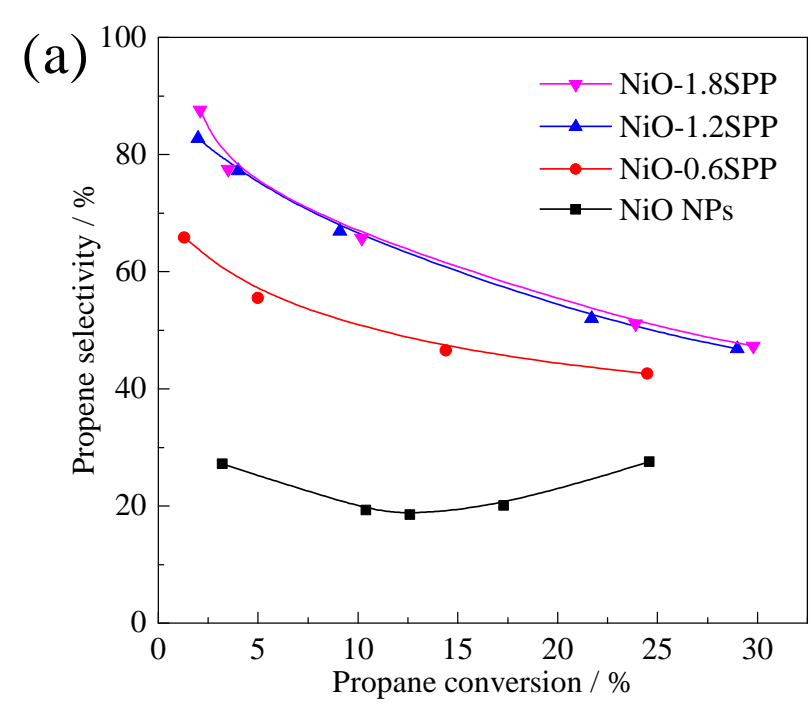

(C)

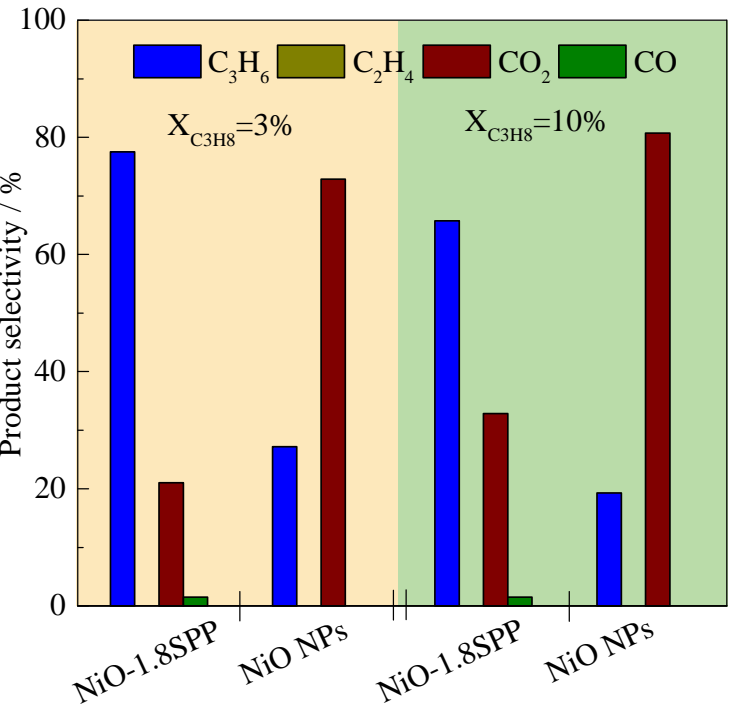

values (Figs. S5 and S6), suggesting that the strong interaction between $\mathrm{NiO}$ and polymeric phosphate can suppress the reactivity of oxygen species.

With their good thermal stability and unique surface electronic structure, NiO-SPP readily serves as great models to investigate the effect of ligand modification in high-temperature catalytic reaction (Fig. S7). Propane oxidative dehydrogenation was chosen because it is an important reaction that remains challenging to control product selectivity [15,20-25]. Fig. 2(a) shows the propene selectivity as a function of propane conversion over NiO NPs and NiO-SPP. In general, due to the higher reactivity of propene over propane, the propene selectivity decreases along with the increase of propane conversion [14]. It is important to highlight that at equivalent conversion of propane, the selectivity of propene on NiO-SPP is generally 2-3 times higher than that on NiO (Fig. 2(a) and (b)). In addition, as the surface content of P increases, the selectivity towards propene increases accordingly (Table S1). These results clearly demonstrate that the modification of
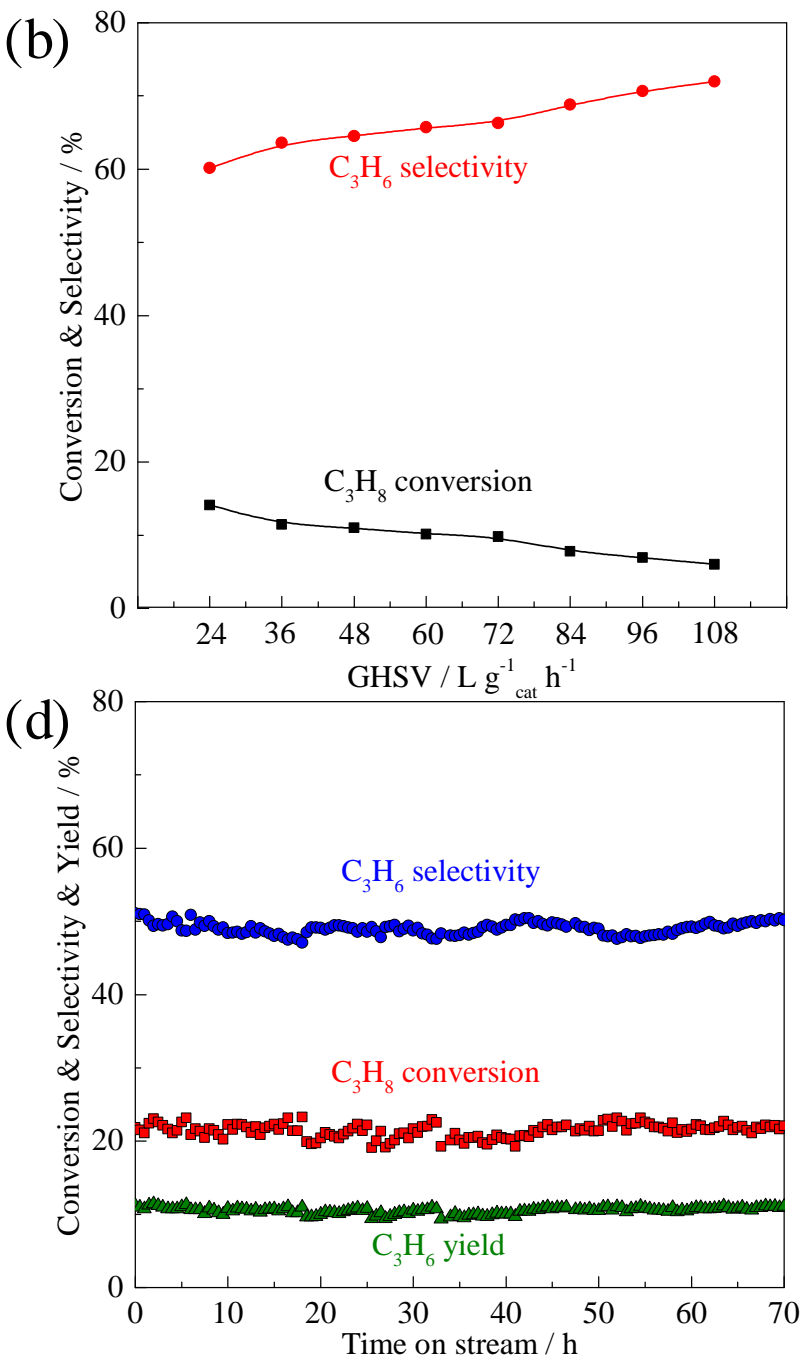

Fig. 2. (a) Propene selectivity as a function of propane conversion over NiO NPs, NiO-0.6SPP, NiO-1.2SPP and NiO-1.8SPP (300-500 $\left.{ }^{\circ} \mathrm{C}\right)$; (b) Propene selectivity and propane conversion as a function of GHSV over NiO-1.8SPP $\left(400{ }^{\circ} \mathrm{C}\right)$; (c) Comparison of product selectivity between NiO NPs and NiO-1.8SPP; (d) Catalytic stability of NiO-1.8SPP $\left(450^{\circ} \mathrm{C}\right.$, GHSV $\left.=60 \mathrm{~L} \mathrm{~g}^{-1} \mathrm{cat}^{-1}\right)$. 
polymeric phosphate can improve the catalytic selectivity towards propene. Propane conversion and propene selectivity remain almost unchanged over $70 \mathrm{~h}$ on-stream for NiO-1.8SPP (Fig. 2(d)), and the surface polymeric phosphate still existed on catalyst (Fig. S8), suggesting that NiO-1.8SPP is a promising candidate for long-term operation. Additionally, we can further improve the propene selectivity of NiO-1.8SPP by increasing the gas hourly space velocity (GHSV), though the propane conversion declines simultaneously (Fig. 2(b)). This result, on the other hand, implies that the facilitated propene desorption is beneficial to the propene selectivity. Interestingly, no cracking products such as ethane and methane are detected on both $\mathrm{NiO}-1.8 \mathrm{SPP}$ and NiO. Control experiment on NiO modified by $\mathrm{H}_{3} \mathrm{PO}_{4}$, however, exhibits considerable cracking products and coke (Figs. S4 and S9). These results demonstrate that a small amount of $\mathrm{Na}^{+}$could prevent the coke formation on the catalyst. Similar results have been previously reported in Pt catalyzed propane dehydrogenation [26,27].

To reveal how the ligand modification enhanced the catalytic selectivity, we carried out the propene oxidation reaction on $\mathrm{NiO}$ and NiO-1.8SPP. In principle, a catalyst with suppressed propene oxidation benefits the catalytic selectivity towards propene. Besides, the investigation of reaction kinetics also provides valuable information for the reaction mechanism. As can be seen from Fig. 3(a), NiO-1.8SPP shows 2-3 fold lower reaction rate than $\mathrm{NiO}$ at full range of propene partial pressure, indicating an intrinsic lower activity of NiO-1.8SPP in propene oxidation. It is important to highlight that the apparent reaction order of propene on NiO-1.8SPP (0.49) is much larger than that on NiO NPs (0.05), suggesting a weaker adsorption of propene on NiO-1.8SPP [28]. This result is further confirmed by $\mathrm{C}_{3} \mathrm{H}_{6}$ temperature-programmed desorption $\left(\mathrm{C}_{3} \mathrm{H}_{6}-\mathrm{TPD}\right)$. The propene desorption temperature of NiO-1.8SPP is roughly $50{ }^{\circ} \mathrm{C}$ lower than that of NiO (Fig. 3(b)), clearly demonstrating that the modification of polymeric phosphate weakens the adsorption of propene. These results could be explained by the ac- id-base property of polymeric phosphate and propene. According to the classic acid base theory, both polymeric phosphate and propene are Lewis base. The surface modification of polymeric phosphate therefore decreases the acidity of $\mathrm{NiO}$ and consequently weakens the interaction between $\mathrm{NiO}$ and propene [29]. To confirm the acidity of NiO NPs and NiO-1.8SPP, we further performed $\mathrm{NH}_{3}$ temperature-programmed desorption ( $\mathrm{NH}_{3}$-TPD). As can be seen from Fig. S10, NiO NPs exhibit a significantly higher amount of $\mathrm{NH}_{3}$ adsorption than NiO-1.8SPP, confirming that NiO NPs have much more acid sites than NiO-1.8SPP. In addition to the weakened acidity, the introduced polymeric phosphate might also isolate the lattice oxygen species of NiO, which is also beneficial to the inhibition of propene oxidation. Meanwhile, kinetic studies on propane oxidative dehydrogenation exhibit similar reaction rates for oxygen and different reaction rates for propane, indicating that the oxygen adsorption and activation is not significantly altered by the ligand modification (Fig. S11).

To rationalize the experimental observations, we further performed density functional calculations (DFT) to determine the structure and adsorption properties of $\mathrm{NiO}$ and NiO-SPP [30-33]. $(\mathrm{NiO})_{10}(\mathrm{OH})_{9}$ and $(\mathrm{NiO})_{10}(\mathrm{OH})_{3}-\left(\mathrm{P}_{2} \mathrm{O}_{7} \mathrm{H}_{2}\right)_{3}$ were employed as models to interpret the local structure of $\mathrm{NiO}$ and NiO-SPP (Fig. S12). Hirshfeld charge analysis suggests that phosphate group withdraws electrons from NiO, consistent with the electron deficiency of NiO revealed by XPS (Fig. 1(d) and (e)). The adsorption energy of propene on NiO-1.8SPP $(1.85 \mathrm{eV})$ is smaller than that on $\mathrm{NiO}(2.30 \mathrm{eV})$, indicating that the phosphate modification weakens the affinity of propene to $\mathrm{NiO}$, which might therefore facilitate the desorption of $\mathrm{C}_{3} \mathrm{H}_{6}$ on NiO-SPP (Table 1). Taking all together, it is convincing that the improved propene selectivity on NiO-1.8SPP is due to the weakened adsorption and oxidation of propene on NiO-1.8SPP.

In summary, we successfully implemented the ligand modification strategy to tune the selectivity of high-temperature gas-phase reaction. NiO modified with polymeric phosphate
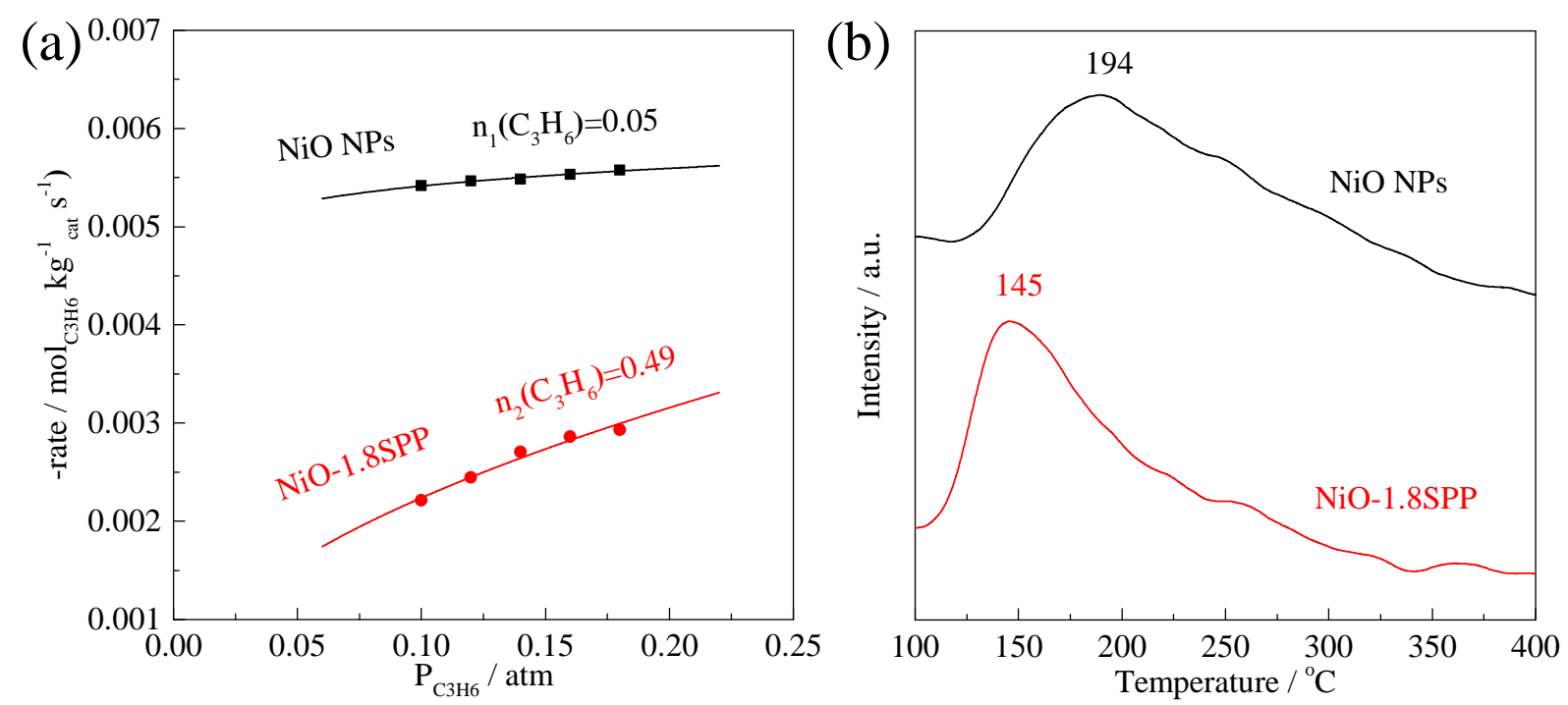

Fig. 3. (a) The influence of $\mathrm{C}_{3} \mathrm{H}_{6}$ partial pressure on catalytic oxidation of propene over $\mathrm{NiO}$ and $\mathrm{NiO}-1.8 \mathrm{SPP}$; (b) $\mathrm{C}_{3} \mathrm{H}_{6}$-TPD profiles over NiO and NiO-1.8SPP. 
Table 1

Hirshfeld charge analysis and adsorption energy of $\mathrm{C}_{3} \mathrm{H}_{6}$.

\begin{tabular}{|c|c|c|c|}
\hline \multirow{2}{*}{ Model } & \multicolumn{2}{|c|}{ Hirshfeld charge } & \multirow{2}{*}{$\begin{array}{c}\text { Adsorption energy of } \\
\mathrm{C}_{3} \mathrm{H}_{6}(\mathrm{eV})\end{array}$} \\
\hline & $(\mathrm{NiO})_{10}$ & $\left(\mathrm{P}_{2} \mathrm{O}_{7} \mathrm{H}_{2}\right)_{3}$ & \\
\hline$(\mathrm{NiO})_{10}(\mathrm{OH})_{9}$ & 0.892 & - & 2.30 \\
\hline$(\mathrm{NiO})_{10}(\mathrm{OH})_{3}-\left(\mathrm{P}_{2} \mathrm{O}_{7} \mathrm{H}_{2}\right)_{3}$ & 1.254 & -1.16 & 1.85 \\
\hline
\end{tabular}

exhibited a high selectivity towards propene, which is $2-3$ times higher than $\mathrm{NiO}$ under the same reaction conditions. Experimental evidence and DFT calculations confirmed that surface polymeric phosphate can facilitate the desorption of propene to improve its selectivity. The success of the present study not only extends the application scope of ligand modification strategy to high-temperature reactions but also provides a useful approach to engineering the surface structure of metal oxide nanoparticles.

\section{Acknowledgments}

The authors thank Dr. Xiaodong Wen and Yunlei Chen for constructive discussions.

\section{References}

[1] Z. Q. Niu, Y. D. Li, Chem. Mater, 2014, 26, 72-83.

[2] P. X. Liu, R. X. Qin, G. Fu, N. F. Zheng, J. Am. Chem. Soc., 2017, 139, 2122-2131.

[3] G. X. Chen, C. F. Xu, X. Q. Huang, J. Y. Ye, L. Gu, G. Li, Z. C. Tang, B. H. Wu, H. Y. Yang, Z. P. Zhao, Z. Y. Zhou, G. Fu, N. F. Zheng, Nat. Mater., 2016, 15, 564-569.

[4] Z. Cao, D. Kim, D. C. Hong, Y. Yu, J. Xu, S. Lin, X. D. Wen, E. M. Nichols, K. Jeong, J. A. Reimer, P. D. Yang, C. J. Chang, J. Am. Chem. Soc., 2016, 138, 8120-8125.

[5] Y. Peng, B. Lu, N. Wang, L. G. Li, S. W. Chen, Phys. Chem. Chem. Phys., 2017, 19, 9336-9348.

[6] T. Yoskamtorn, S. Yamazoe, R. Takahata, J. I. Nishigaki, A. Thivasasith, J. Limtrakul, T. Tsukuda, ACS Catal, 2014, 4, 3696-3700.

[7] A. Fedorov, H. J. Liu, H. K. Lo, C. Copéret, J. Am. Chem. Soc., 2016, $138,16502-16507$.

[8] B. H. Wu, H. Q. Huang, J. Yang, N. F. Zheng, G. Fu, Angew. Chem. Int.
Ed., 2012, 51, 3440-3443.

[9] J. J. Liu, V. Fung, Y. Wang, K. M. Du, S. R. Zhang, L. Nguyen, Y. Tang, J. Fan, D. Jiang, F. F. Tao, Appl. Catal. B, 2018, 237, 957-969.

[10] J. J. Liu, S. R. Zhang, Y. Zhou, V. Fung, L. Nguyen, D. Jiang, W. J. Shen, J. Fan, F. F. Tao, ACS Catal., 2016, 6, 4218-4228.

[11] S. T. Marshall, M. O'Brien, B. Oetter, A. Corpuz, R. M. Richards, D. K. Schwartz, J. W. Medline, Nat. Mater., 2010, 9, 853-858.

[12] F. Cavani, F. Trifirò, Catal. Today, 1995, 24, 307-313.

[13] J. J. H. B. Sattler, J. Ruiz-Martinez, E. Santillan-Jimenez, B. M. Weckhuysen, Chem. Rev., 2014, 114, 10613-10653.

[14] H. H. Kung, Adv. Catal., 1994, 40, 1-38.

[15] F. Cavani, N. Ballarini, A. Cericola, Catal. Today, 2007, 127, 113-131.

[16] X. H. Cao, Y. M. Shi, W. H. Shi, G. Lu, X. Huang, Q. Y. Yan, Q. C. Zhang, H. Zhang, Small, 2011, 7, 3163-3168.

[17] I. Maarouf, A. Oulmekki, J. Toyir, F. Lefebvre, A. Harrach, M. Ijjaali, J. Mater. Environ. Sci., 2017, 8, 2722-2728.

[18] E. J. Baran, R. C. Mercader, A. Massaferro, E. Kremer, Spectrochim. Acta Pt. A, 2004, 60, 1001-1005.

[19] J. H. Li, C. C. Wang, C. J. Huang, Y. F. Sun, W. Z. Weng, H. L. Wan, Appl. Catal. A, 2010, 382, 99-105.

[20] M. Sun, J. Z. Zhang, P. Putaj, V. Caps, F. Lefebvre, J. Pelletier, J. M. Basset, Chem. Rev., 2014, 114, 981-1019.

[21] B. Frank, J. Zhang, R. Blume, R. Schlögl, D. S. Su, Angew. Chem. Int. Ed., 2009, 48, 6913-6917.

[22] J. T. Grant, C. A. Carrero, F. Goeltl, J. Venegas, P. Mueller, S. P. Burt, S. E. Specht, W. P. McDermott, A. Chieregato, I. Hermans, Science, 2016, 354, 1570-1573.

[23] L. Shi, D. Q. Wang, W. Song, D. Shao, W. P. Zhang, A. H. Lu, ChemCatChem, 2017, 9, 1788-1793.

[24] L. Shi, D. Q. Wang, A. H. Lu, Chin. J. Catal., 2018, 39, 908-913.

[25] Q. H. Zhang, C. J. Cao, T. Xu, M. Sun, J. Z. Zhang, Y. Wang, H. L. Wan, Chem. Commun., 2009, 2376-2378.

[26] Y. Z. Duan, Y. M. Zhou, Y. W. Zhang, X. L. Sheng, M. W. Xue, Catal. Lett., 2011, 141, 120-127.

[27] L. Y. Bai, Y. M. Zhou, Y. W. Zhang, H. Liu, X. L. Sheng, Ind. Eng. Chem. Res., 2009, 48, 9885-9891.

[28] Y. Y. Li, H. Cheng, T. Yao, Z. H. Sun, W. S. Yan, Y. Jiang, Y. Xie, Y. F. Sun, Y. Y. Huang, S. J. Liu, J. Zhang, Y. N. Xie, T. D. Hu, L. N. Yang, Z. Y. Wu, S. Q. Wei, J. Am. Chem. Soc., 2012, 134, 17997-18003.

[29] J. Datka, A. M. Turek, J. M. Jehng, I. E. Wachs, J. Catal., 1992, 135, 186-199.

[30] M. C. Payne, M. P. Teter, D. C. Allan, T. Arias, J. Joannopoulos, Rev.

\section{Graphical Abstract}

Chin. J. Catal., 2019, 40: 1057-1062 doi: 10.1016/S1872-2067(18)63199-7

Tuning catalytic selectivity of propane oxidative dehydrogenation via surface polymeric phosphate modification on nickel oxide nanoparticles

Kaimin Du, Mengjia Hao, Zhinian Li, Wei Hong, Juanjuan Liu, Liping Xiao, Shihui Zou *, Hisayoshi Kobayashi *, Jie Fan*

Zhejiang University; Hangzhou Dianzi University; Kyoto Institute of Technology

Polymeric phosphate is demonstrated as an efficient and stable ligand to tune the selectivity of propane oxidative dehydrogenation. Beneficial from the weakened affinity of propene, NiO modified with polymeric phosphate shows a selectivity 2-3 times higher than $\mathrm{NiO}$ towards the production of propene.

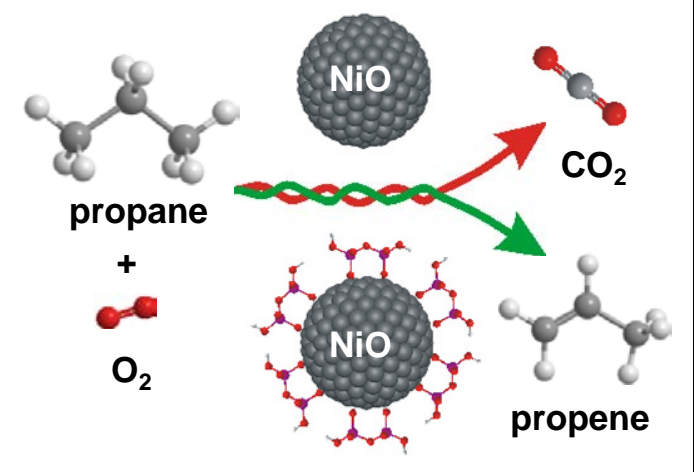


Mod. Phys., 1992, 64, 1045-1097.

[31] V. Milman, B. Winkler, J. A. White, C. J. Pickard, M. C. Payne, E. V. Akhmatskaya, R. H. Nobes, Int. J. Quantum Chem., 2000, 77, 895-910.
[32] J. P. Perdew, K. Burke, M. Ernzerhof, Phys. Rev. Lett., 1996, 77, 3865-3868.

[33] D. Vanderbilt, Phys. Rev. B, 1990, 41, 7892-7895.

\title{
聚磷酸配体修饰调控氧化镍纳米颗粒在丙烷氧化脱氢反应中的选择性
}

\author{
杜凯敏 ${ }^{\mathrm{a}}$, 郝梦佳 ${ }^{\mathrm{a}}$ ，李志年 ${ }^{\mathrm{a}}$, 洪 伟 ${ }^{\mathrm{a}}$, 刘娟娟 ${ }^{\mathrm{b}}$, 肖丽萍 ${ }^{\mathrm{a}}$, 邹世辉 ${ }^{\mathrm{a}}$,

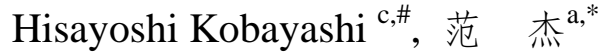 \\ a浙江大学化学系浙江省应用化学重点实验室, 浙江杭州310027, 中国 \\ b杭州电子科技大学材料与环境工程学院, 浙江杭州310018, 中国 \\ c 京都工艺纤维大学化学与材料科学系, 京都606-8585, 日本
}

摘要: 利用有机配体对金属纳米颗粒表面进行修饰来构建配体-金属界面是一种简单且高效的调控纳米催化剂催化选择 性和稳定性的策略. 这种调控主要来源于配体与金属间的电子效应及位阻效应. 然而到目前为止, 这一策略多局限于液相 反应, 对于高温 $\left(>300^{\circ} \mathrm{C}\right)$ 气相反应涉及不多, 这主要是因为高温反应条件下有机配体分子不稳定. 因此, 开发稳定的配体 及修饰方法是克服该局限性并将配体修饰策略应用到一些重要的高温反应中的关键.

本文以聚磷酸根作为一种高效且热稳定性良好的无机配体对氧化镍纳米颗粒表面进行修饰. 红外光谱、X射线光电子 能谱、X射线衍射和透射电镜等分析证实, 聚磷酸物种原位修饰在氧化镍表面之后, 氧化镍纳米颗粒的物性结构未发生明显 变化, 但聚磷酸物种与 $\mathrm{NiO}$ 之间存在一定的电子相互作用. 将具有不同磷修饰量的氧化镍催化剂应用于极具挑战的丙烷氧 化脱氢制丙烯反应中. 结果表明, 聚磷酸修饰后, 氧化镍纳米催化剂的丙烯选择性有了极大提高. 相比单纯纳米氧化镍 (10\%丙烷转化率, 19\%丙烯选择性), 经聚磷酸配体修饰后, 在相同丙烷转化率下产物丙烯的选择性提高了2-3倍(10\%丙烷 转化率, $66 \%$ 丙烯选择性). 稳定性实验 $\left(450^{\circ} \mathrm{C}, 70 \mathrm{~h}\right)$ 和热重分析等结果表明, 聚磷酸物种具有良好的热稳定性, 可作为稳定 的配体用于长时间高温催化测试. 进一步采用动力学实验和丙烯脱附等方法及理论计算对反应机理进行了探究, 认为配 体的引入可以减弱丙烯在催化剂表面的吸附亲和性, 进而提高丙烯选择性. 本文研究结果证实了配体修饰这一策略在高 温气相反应中应用的可行性, 该策略有望在其他一些重要高温反应中得到进一步应用.

关键词: 氧化镍纳米颗粒; 表面聚磷酸; 丙烷氧化脱氢; 选择性调控; 吸附

收稿日期: 2018-10-04. 接受日期: 2018-11-12. 出版日期: 2019-07-05.

*通讯联系人. 电话/传真: (0571)87952338; 电子信箱: jfan@zju.edu.cn

\#通讯联系人. 电子信箱: hisabbit@yahoo.co.jp

\$通讯联系人. 电子信箱: xueshan199@163.com

基金来源：国家自然科学基金(91545113，21703050); 中国博士后科学基金(2017M610363,2018T110584); Shell Global Solutions International B. V. (PT71423, PT74557); 霍英东教育基金(131015); 宁波科技计划项目(2017C50014).

本文的电子版全文由Elsevier出版社在ScienceDirect上出版(http://www.sciencedirect.com/science/journal/18722067). 